\title{
PHOTOVOLTAICS IN PRESENT DAYS AND THEIR COEXISTENCE WITH POWER SYSTEM
}

The article deals with the issue of presentation of photovoltaic power and photovoltaic power plants, describes their main features, their advantages and disadvantages, and also deals with the possible massive deployment of these power sources to the power system and their impacts on power system operation.

\section{Introduction}

Photovoltaic power plants (PV) have become nowadays a major phenomenon. Progress in science, especially in semiconductor technologies, enabled the development of various types of photovoltaic applications. In 70's of the 20th century during the oil crisis large number of photovoltaic power plants was built especially in Western Europe and in the USA, of which many are still operating successfully. Advancements in this area quietened after decay of crisis.

Today, however, the situation is set that makes renewable sources very attractive. Increase in the consumption of all non-renewable sources results in the raising pressure on the stocks of these commodities. For example if we compare years 1999 and 2009 we can see that the consumptions of fuels like oil, gas and coal increased over $23 \%$. When comparing years 1989 and 2009 we get $40 \%$ difference. Looking at the stocks of primary energy sources we get next image. According to [4] the reserves of oil are in proportion to today's consumption available for 46 years, reserves of natural gas are available for 63 years and reserves of coal are predicted for 119 years. These numbers are obviously predicted only for constant consumption. But the rapid development of economies such as China and India means that the reserves will decrease from year to year. Not even reserves of uranium ore don't look very optimistically. These are predicted for 85 years [5].

Now we can return back to the photovoltaic energy. In the past, a factor that limited development in this area was high cost of acquisition of photovoltaic technology. An effort to relieve the dependence on imported energy resources has led the governments to adapt the legislation to increase the interest on technology of photovoltaic power plants of potential investors. High values are motivating and are increasingly evocating creation of projects to use the energy almost unused till today. However, photovoltaic brings with it many issues which have to be solved most effectively.

\section{Sun Energy in Slovakia}

The sun is for the Earth unimaginable and for mankind endless source of energy. The amount of solar radiation reaching the earth is not changing and is approximately $118000 \mathrm{TW}$, which is several thousand times more than the current requirements for energy consumption [6]. Distribution of solar energy is homogeneous, not as is the case with fossil fuels, but energy density is hundredfold lower in the comparison to conventional thermal or nuclear sources. The impact energy on Earth's atmosphere upper edge is at any time around $1367.13 \mathrm{~W}$ on $1 \mathrm{~m}^{2}$. This is so-called solar constant. It must be said, however, that not all the energy that hits the surface of the Earth's atmosphere also hits the Earth's crust. Approximately $30 \%$ of energy is immediately reflected from the atmosphere and goes back into space. The rest of it warms up the oceans, makes the wind blowing or is diffused in atmosphere. So Earth's surface is directly hit only with a portion of incident solar radiation. Radiation which is diffused in atmosphere due to molecules and suspensoids and radiation that is reflected from the Earth's crust and goes back to space or is re-diffused in atmosphere is called diffuse sky radiation. Summary of direct and diffuse sky radiation is the global radiation [7].

The big difference in amounts of hitting solar radiation is also created due to different latitudes. In Europe, we are going to compare two counterparts. Amount of solar radiation perpendicularly incident in northern Sweden and Russia is reaching 400$600 \mathrm{kWh} / \mathrm{m}^{2}$ per year but in the Mediterranean region it is approximately $2000 \mathrm{kWh} / \mathrm{m}^{2}$ per year. In Slovakia, the value of the intensity of solar radiation varies between $1000-1205 \mathrm{kWh} / \mathrm{m}^{2}$ per year [6]. After some calculations we can determine that it is several times more energy than we are nowadays able to consume.

Solar power represents the largest potential source of renewable energy in Slovakia. Technically exploitable potential for elec-

\footnotetext{
* Jan Turcek, Matej Hrasko, Juraj Altus

Department of Power Electrical Systems, Faculty of Electrical Engineering, University of Zilina, Slovakia, Email: Jan.Turcek@fel.uniza.sk
} 
tricity production from photovoltaic power plants was for the Slovak Republic established as $1540 \mathrm{GWh}$ per year [8].

\section{Exploitation of Sun Energy for Electricity Production}

There are several ways of production of the electricity from sunlight. We can distinguish between indirect conversion of sunlight into electrical energy and direct conversion. For example the indirect conversion includes concentrated solar power plants. These are a tower-type plants or plants using trough mirrors. These plants operate on the principle of mirror, which is turning against the sun to warm up working medium, which flows through pipes that are located in the focus of the mirror. This heated fluid drives the turbine to produce electricity. Another way may be a solar power plant that uses the stack effect. Sufficiently high tower - the chimney is surrounded by a system of pipelines placed on the surface through which the air flows. Air in the pipelines is thanks to the sun's rays heated and then due to stack effect rising through chimney upwards. Wind turbine that is located in the chimney is spinning because of upward wind blowing and produces electricity.

All of these mentioned methods are very difficult to be realized in Slovakia and can be placed for instance in desert areas with high solar radiation intensity and low pressure for land occupation.

Direct conversion means that the energy of sunlight is converted by semiconductor materials into electricity. As it is direct method, photovoltaic power plant is not a burden for environment, it emits no gases and the only drawback is the production of photovoltaic technology.

We can nowadays distinguish several types of photovoltaic cells. First types are cells made from crystalline silicon. These are cells made from monocrystalline silicon referred as Mono c-Si, whose efficiency varies from $12 \%$ to $19 \%$, polycrystalline or multicrystalline silicon (multi c-Si) whose efficiency varies from 11\% to $15 \%$ and ribbon sheets (ribbon-sheet c-Si). These cells are most prevalent, and their share is about $90 \%$ of the total quantity of modules.

Moreover there are other materials in today's market. For example amorphous silicon, cadmium telluride (CdTe), copper indium (di)selenide (CIS) or copper indium gallium (di)selenide (CIGS) which is based on material CuInSe 2 that absorbs $99 \%$ of light in its first micron. Another type of modules is based on multi junction cells (a-Si/m-Si).

Maximum efficiency is achieved in concentrator solar cells. These are using optical concentrators for example Fresnel lens. Their disadvantage is that they can not use diffuse sky radiation and must be constantly turned against the sun. Such systems, however, reach up to $31 \%$ efficiency [6][9].

The essence of electricity production through semiconductor solar cell is the fact that the impact of sunlight on the PN transi- tion results in the emergence of direct electrical current between $\mathrm{P}$ and $\mathrm{N}$ layers of semiconductor. Direct current can be consequently changed by converter, strictly speaking inverter, to commonly used AC supply voltage $230 \mathrm{~V}, 50 \mathrm{~Hz}$. Thus equipped photovoltaic power cell can be connected into the mains.

The amount of electricity $E(\mathrm{kWh})$ produced by photovoltaic system with a nominal power $P_{k}\left(\mathrm{Wp} / 1000 \mathrm{Wm}^{-2}\right)$ and the total efficiency $r_{p}$, which is the ratio between real and nominal power, can be derived from global solar radiation $G\left(\mathrm{kWh} / \mathrm{hm}^{-2}\right)$.

$$
E(t)=P_{k} r_{p} G \quad[\mathrm{kWh}]
$$

Real power is influenced by the size of the external temperature, solar radiation variability, cloudiness, which has a significant impact and because of its local character is almost unpredictable, by the cabling, by the voltage converters, etc. [6]

Increase of installed capacity can be shown on following numbers. At the end of the year 2009 installed capacity of photovoltaic power plants was 22928.9 MWp worldwide and in Europe it was $16065.8 \mathrm{MWp}$. In 2008 worldwide installed capacity was 15599.1 MWp and in Europe 10428.7 MWp. Regarding the installed capacity in 2009 it means increase over $47 \%$ worldwide and over $54 \%$ in the Europe. Even more interesting numbers are obtained in comparison with the year 1999. Worldwide installed capacity was 1013.6 MWp and 143.4 MWp from that volume was in Europe. So in comparison with installed capacity at the end of year 2009 it is worldwide increase over $2000 \%$ and in the Europe the increase is over enormous $11000 \%$ [4]. The results are illustratively shown in the Fig. 1 and Fig. 2.

Further increase of the installed capacity of photovoltaic power plants is expected in the next years. Currently the biggest photovoltaic power plant is the Finsterwalde Solar Park with installed capacity $80.7 \mathrm{MW}_{\mathrm{p}}$ [10]. However gigantic power plant is in preparation in China. It is going to be built in the Ordos region near border with Mongolia and its installed capacity should be 2 GWp. Its completion is planned in 2019 [11].

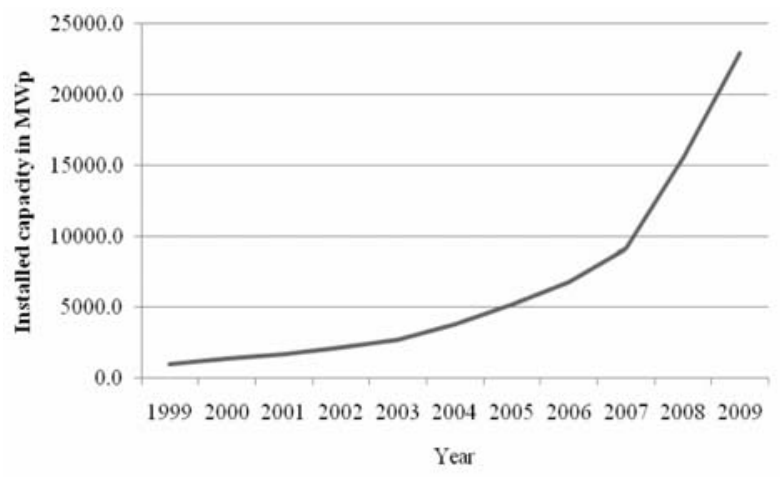

Fig. 1 Development of installed capacity of PVS in the World 


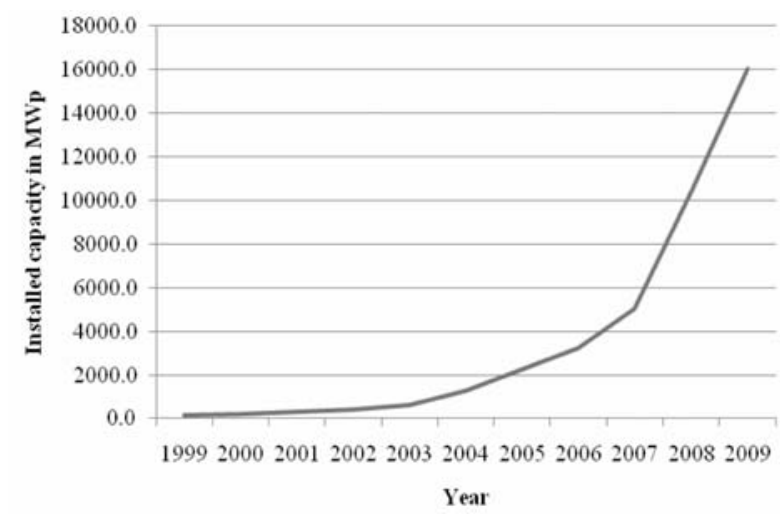

Fig. 2 Development of installed capacity of PVs in Europe

\section{Photovoltaics in Slovakia}

Photovoltaic power plants are dependent on the sunlight and its intensity. This, however, varies considerably during the day.

In Fig. 3, we can see the daily load curve of Slovakian power system. As it can be seen the maximum load occurs from 19 to 20 o'clock. On the other hand the smallest load occurs at night around 4 o'clock in the morning. At six to seven o'clock a morning peak occurs due to initiation of industrial plants operations and at lunch hour the energy consumption decreases.

Another important fact is also a great difference between the system load in summer and winter months. Annual minimum of consumption occurs in July, but increasing amounts of air conditioning units are likely to increase energy demand in summer months. On the contrary maximal energy demands are in winter months. From the long-term observations it's documented that the maximum load of the system occurs in the January. As a result of global warming winters are milder, but still there may be situations when the arrival of severe frosts results in significant energy consumption increase.

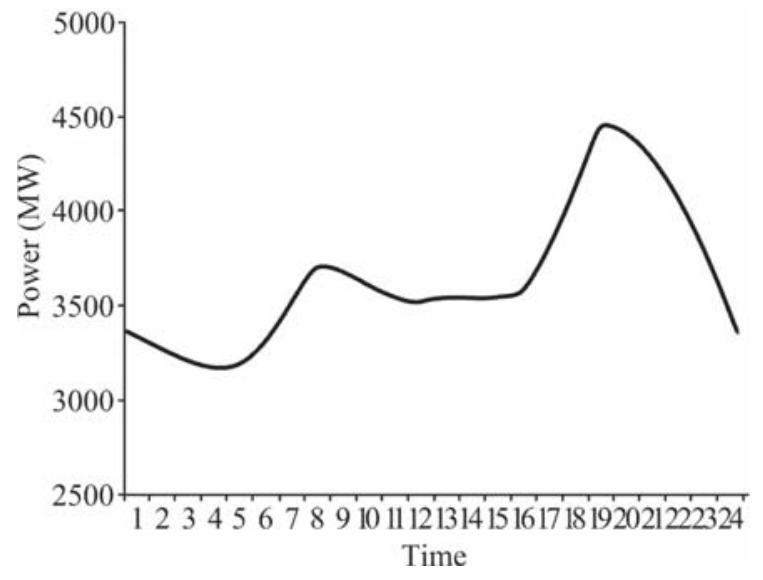

Fig. 3 Daily load curve
When talking about behaviour of the photovoltaics, it is precisely the opposite. In the summer, the influence of stronger intensity of solar radiation and the influence of longer day duration causes the fact that the electricity production reaches its maximum. In winter, resulting from shorter day duration and dominant diffuse sky radiation, amount of electric energy produced by photovoltaic power plants reaches minimum. As seen in Fig. 4 photovoltaic power output varies greatly during twenty-four hours. At the dawn it begins to raise from zero, at noon the sunlight intensity reaches maximum values, which results in maximal electricity production, and when the evening comes it starts to fall back till zero is achieved.

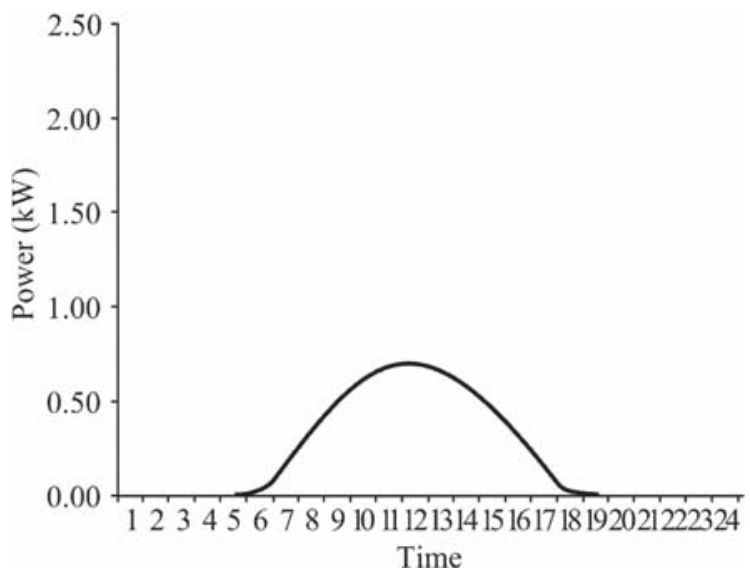

Fig. 4 Map line of photovoltaic electricity production during the day

By comparing these two curves, we find out that these waveforms are not similar at all. Although a photovoltaic power plant is working during the daylight, its power performance during the morning peak reaches the minimum values. In winter, the starting point of photovoltaic power curve shifts to 8 o'clock and ending point is moving already to 16 o'clock. As mentioned photovoltaic maximum output power is achieved in the summer, but this does not correspond with the system load which is lowest in summer. Another important part of the daily load curve is the evening peak, which cannot be covered from photovoltaic power plants. These facts will create serious problems for operation of power system if there is a massive deployment of photovoltaic power plants.

Nowadays there is only small installed capacity of photovoltaic power plants in Slovakia in comparison with neighbouring countries. In 2006 there were installed according to [12] $64 \mathrm{kWp}$. By the end of 2011 installed capacity of $120 \mathrm{MW}$ is assumed. List of 36 power plants with allotted certificates was published already in December 2009. Sum of their power performance is previously mentioned $120 \mathrm{MW}$ [13].

Most resources connected to the electricity system will have installed power from $1 \mathrm{MW}$ to $4 \mathrm{MW}$. Others are smaller sources or sources operated in standalone mode, i.e. not connected to the electricity system. These are autonomous resources in inaccessible locations or telephones. 
Photovoltaic power plant in Cerenany is one example of photovoltaic power plants connected to the network with output of $500 \mathrm{kWp}$ which was completed in May 2010. Another example is photovoltaic power plant in the eastern Slovakia in the village of Mala Domasa with the performance of $735 \mathrm{kWp}$. It is quite interesting because 3000 panels are located here and are placed on trackers which are tracking the movement of Sun and are moving panels always perpendicular to the sun beams. Moreover it is the largest photovoltaic power plant in eastern Slovakia.

In close connection with photovoltaic power plants there are wind power plants. As photovoltaics, these are also sources, that are helping to decentralize production of electricity, but with their major properties, they are considerably influencing electrical power system. Installed capacity of wind power in Slovakia is currently $3 \mathrm{MW}$

Photovoltaic and wind power sources are hardly predictable and therefore are referred as unpredictable renewable energy sources. While the first are dependent on the intensity of solar radiation, exterior temperature and also the cloudiness, the second depend mainly on the speed of airflow, but the final production characteristics are also affected by many other factors. Most of these factors are very difficult to predict. Therefore the operation of these power plants causes bigger pressure on the operation of power system.

Until now there has not been installed any larger unpredictable renewable energy source in Slovakia and this implies in lack of experience with their operation. But from current experiences we know what consequences may have the massive deployment of wind power plants into electrical power system.

In Germany, at the end of the year 2009, there was installed 25813 MW in wind power plants. Germany also holds the world's primacy in installed capacity of photovoltaic power plants. Situation in Europe in the amount of installed capacity is as following. Installed capacity of photovoltaic power plants was in the Czech Republic at the end of $2009411 \mathrm{MWp}$ [14], in Italy at the end of $20091181 \mathrm{MWp}$ [15] and at the end of 2008 Spain had got 3354 MWp [16]. To compare, the sum of off grid installed and grid connected applications in Germany was $9845 \mathrm{MWp}$ at the end of 2009 [17].

Nowadays we are experiencing the impacts of this massive installation. Germany is surrounded mostly by countries whose energy balance is settled, in addition to the two adjacent exporters France and the Czech Republic, and one smaller exporter Poland. So the question raises what to do with the electric energy, when there is a massive production from wind power and solar energy. Forasmuch as in the south Europe there are mostly countries whose energy balance is strongly deficit, there are efforts to send the generated energy to them. Of course this is happening through power grid. This may cause serious problems, because the requirements on the power lines such as these can eventuate in lowering reliability. As a result of an accumulation of adverse factors there can be disintegration into island operations and in the worst case so called blackout.
The most serious problem is to adjust the production curves of these resources to the needs of the power system. As the sources are mainly small scaled, decentralized, it is very difficult to find a suitable way to control their performance. In the case of photovoltaic power they are typically sources with installed capacity around $\mathrm{kW}$. It may seem that this is a small number, but due to the massive deployment, and so the resulting numbers, the sum of their installed capacity may be very large.

The big problem is that power performance is very variable due to time. If we neglect other factors and we would count only with the sun's movement their power performance would have been easy to foreseen with a relatively high value of certainty. Thus the Pvs can be used most efficiently. But the reality is different and operating performance and the quantity of produced power are under big influence of other factors such as temperature, and especially cloudiness. This means greater demands on the transmission system operator and distribution system operators.

Another thing is daily power performance of photovoltaic power plants. From that it is obvious that it would be necessary to store the energy at the time of their maximal production. In the present day the most effective way is to consume this energy by pumping and so to store it in tanks of pumped storage plants, that would commercialize it again in the morning and evening, especially when there is in shortage.

Here come the issues of effective utilization of pumped storage power plants. In Slovakia there are 4 pumped storage power plants. One is connected to the $400 \mathrm{kV}$ level and three to the $110 \mathrm{kV}$ level. Most photovoltaic power plants will be connected to a $22 \mathrm{kV}$ level. Pumped storage power plants have the nature of centralized sources and photovoltaic power stations are decentralized resources. But this is not only about pumped storage power plants. The system functions thanks to numerous regulators that will have to eventually regulate the power fluctuations caused by photovoltaic power plants. These are issues of primary and secondary frequency regulation.

One possibility of best usage of solar energy is the establishment of virtual power plant. It would involve the combination of a number of energy sources into a single unit that would offer certain guaranteed parameters equal to required production diagrams.

Other fact is that in the winter, photovoltaic power plants achieve low production levels and consumption is higher than in summer. So the sources which can replace these power outages are needed.

Another thing is that the production of photovoltaic power plants depends not only on the season, but also on the ambient temperature and mostly on cloudiness. Predictability of cloudiness is very difficult, since its local character, and that's why the consequent prediction of electric energy production is not exact. This again causes pressure on network operators.

Given the rapid changes in power performance is necessary to establish sufficient reserves of production capacities, especially 
in quickly starting sources, such as pumped storage power plants, water power plants with peak-load operation and combined cycles.

As mentioned above, only small number of unpredictable renewable energy sources was installed in Slovakia. The power system was designed to operate with conventional thermal, nuclear and hydroelectric power plants. All these are resources whose production is easily predictable. Naturally the producer does not determine the amount of generated energy but the consumer does. Therefore, Slovakia has installed capacities that can meet these consumer demands.

With the arrival of photovoltaic power plants, however, new problem rises. Requirements for the support services that can ensure stability of power system operation will grow. These demands will increase not only because of requirements on the consumption side but also on the production side. All these changes will obviously result in increased operating costs and maybe even in construction of new production units.

\section{Conclusion}

Installation of photovoltaic power plants signifies for Slovakia, a country which imports about 90 percent of all energy sources, a great potential. It is the way to relieve dependence on the energy sources from other countries. Photovoltaic is also the cleanest way how to get the electric energy. But its operation causes considerable problems for the transmission power system operators and operators of distribution systems. Possible way to compensate these impacts is to buy the high price regulatory electric energy from other countries. Another possibility is to build new blocks of power plants that will replace production of photovoltaic power plants during their inactivity or on the other hand to use generated electric energy in time of its maximal production. Building of such sources may however take several years.

\section{References}

[1] RYBAR, P., RYBAR, R., TAUS, P.: Alternative Energy Sources - Part 1 (in Slovak), TU FBERG, Kosice, 2001, p.121

[2] JANICEK, F. et al.: Renewable Energy Sources - Part 1 (in Slovak), FEI STU, Bratislava 2007

[3] MULLEROVA, J., SUTTA, P., JURECKA, S.: Thin Film Silicon in Photovoltaics: The Role of Structure and Microstructure, Communications - Scientific Letters of the University of Zilina, No. 1, 2006, pp. 5-9

[4] http://www.bp.com/productlanding.do?categoryId=6929\&contentId=7044622, (accessed 10/10)

[5] Uranium 2005 - Resources, Production and Demand, ISBN 92-64-024263, http://www.nea.fr/ndd/reports/2006/uranium2005english.pdf, (accessed 08/10)

[6] http://www.solarenergia.sk/slnecna-energia/, (accessed 03/10)

[7] http://www.seps.sk/zp/fond/2002/slnko/slnko.html, (accessed 03/10)

[8] HUDCOVSKY, S.: Renewable Energy Sources and their Application in Power System (in Slovak), Coneco-Racioenergia 2009 Bratislava, www.tzs.sk/upload/TZSprezentacie/ Hudcovsky-EGU.ppt, (accessed 03/10)

[9] http://www.epia.org/solar-pv/pv-technologies-cells-and-modules.html, (accessed 11/10)

[10] http://www.pv-tech.org/news/_a/good_energies_nibc_infrastructure_partners_acquire_finsterwalde_ii_and_fins/, (accessed $11 / 10)$

[11] http://news.cnet.com/8301-11128_3-10347438-54.html, (accessed 10/10)

[12] http://www.energies-renouvelables.org/observ-er/stat_baro/observ/baro178.pdf, (accessed 11/10)

[13] http://www.sepsas.sk/seps/informacia2009_12_11.asp?Kod=25\&Nadrad=423, (accessed 09/10)

[14] http://www.czrea.org/cs/druhy-oze/fotovoltaika/inst-vykon2009-eru, (accessed 11/10)

[15] http://www.iea-pvps.org/countries/download/nsr09/NSR\%\%20202009\%\%2020Italy.pdf, (accessed 10/10)

[16] http://www.iea-pvps.org/countries/download/nsr08/NSR\%\% 20Spain 202008_v2.pdf, (accessed 10/10)

[17] http://www.iea-pvps.org/countries/download/nsr09/Country\% 20Report\% 202009.pdf 20Germany\%, (accessed 10/10). 